Short communication

\title{
Does light-stick content pose any threat to marine organisms?
}

\author{
Grasiela L.L. Pinho, Priscilla M. Ihara, Gilberto Fillmann* \\ Laboratório de Microcontaminantes Orgânicos e Ecotoxicologia Aquática, Instituto de Oceanografia, Universidade Federal do Rio Grande (FURG), \\ Av. Itália km 8, Carreiros, 96.201-900 Rio Grande, RS, Brazil
}

\section{A R T I C L E I N F O}

\section{Article history:}

Received 18 February 2008

Received in revised form 21 July 2008

Accepted 8 August 2008

Available online 19 August 2008

\section{Keywords:}

Artemia

Cyst hatchability

$\mathrm{LC}_{50}$

Light-stick

Toxicity

\begin{abstract}
A B S T R A C T
Light-stick is a light attractor used in longline fishing which is often dumped or lost into the ocean after used, becoming a potential pollutant to marine organisms. In the present study, toxicity was evaluated by exposing Artemia to light-stick contents. The effects were observed on the survival of nauplii and hatchability of cysts. The $\mathrm{LC}_{50}$ was $0.063 \mathrm{mLL}^{-1}$ after $24 \mathrm{~h}$ of exposure, whilst hatchability was $100 \%$ reduced after $48 \mathrm{~h}$ of exposure to $0.8 \mathrm{~mL} \mathrm{~L}^{-1}$. The results showed that its content can be toxic to marine organisms, especially under low dilution conditions or direct contact.
\end{abstract}

(c) 2008 Elsevier B.V. All rights reserved.

\section{Introduction}

Pelagic longline fishing involves a single main fishing line with thousands of individually hooked lines branching off from the main line (Bigelow et al., 2006). This fishing method is widely used in every ocean basin and commonly targets tunas, swordfish and dolphin fish (Boggs and Ito, 1993). A common practice in longline fisheries is to attach glowing light-sticks to the branch lines above the hooks, in order to attract fish (Witzell, 1999). A recent analysis of Hawaiian swordfish longline fisheries revealed that the average longline was $74.5 \mathrm{~km}$ long, contained 397 light-sticks (Bigelow et al., 2006). Thus, a large number of light-sticks are used in at least some fisheries. However, these devices are often found as litter in coastshores since it can be either dumped or accidentally lost in the oceans after its use (Ivar do Sul et al., 2007; Santos et al., in press).

The light-stick attractor is a commercially available product which produces a long-lasting light of various colors by mixing two different chemical solutions (Ermoshkin et al., 2006). The light is produced when the internal ampoule containing the activator solution is broken and the two solutions react. The activator solution into the glass ampoule contains hydrogen peroxide in dimethyl phthalate solvent (1,2-benzenedicarboxylic acid dimethyl ester). The second solution contains bis(2-carbopentyloxy-3,5,6trichlorophenyl) oxalate (oxalic acid bis(2,4,6-trichlorophenyl)

\footnotetext{
* Corresponding author. Tel.: +55 533233 6738; fax: +55 5332336601

E-mail address: gilberto@pq.cnpq.br (G. Fillmann).
}

ester) and a dye solution in a dibutyl phthalate solvent (1,2benzenedicarboxylic acid dibutyl ester) (Pedersen et al., 2003).

Studies involving light-stick are often intended to evaluate its efficiency to attract fish (Hazin et al., 2005). It is worth mentioning a study regarding accidental catches of turtles when they are inadvertently attracted by luminosity (Wang et al., 2007). Although some evidence of skin toxicity (such as erythemas and presence of vesicles) has been found in Wistar rats exposed to light-stick content (Ivar do Sul et al., 2007), there is not any published data evaluating the potential harm or toxicity of light-stick contents to marine organisms.

Therefore, on the basis of the toxicity previously verified to skins of rats and considering the high number of light-sticks used in longline fishing, light-sticks may be considered a type of marine pollutant which needs further investigations about its toxicity. Considering light-stick content as a new type of marine pollutant, the present investigation reports the first results on light-stick toxicity to a marine species. The brine shrimp Artemia sp. has been chosen due to its relevant geographical distribution and often used in ecotoxicological tests.

\section{Materials and methods}

Experimental tests were conducted at the "Universidade Federal do Rio Grande", Southern Brazil. Larvae of brine shrimp, Artemia sp., were hatched from cysts (INVE) and 48-h-old larvae only were used for the tests.

Light-sticks used in the experiments were collected at "Costa dos Coqueiros" beaches (northeast Brazil, $\sim 12^{\circ} \mathrm{S}$ ), region where was found 2000 devices in the 95-km-long shoreline (January 2005; Ivar do Sul et al., 2007). Light-stick contents utilized consisted of used light-sticks exposed to the environment for an unknown 
period of time, which might changes their original chemical composition. For each test, the contents of four orange light-stick tubes (the most frequent type found on the sampled beaches) were pooled and soon after mixed for $2 \mathrm{~h}$ with filtered saltwater (salinity 25) to achieve the exposure concentrations. Organisms and cysts were separately exposed to the same solution of orange light-stick contents. No content composition analyses were performed in this study.

Toxicity experiment with Artemia larvae was performed in a multiwell plate (12 wells). Each well was filled with $250 \mu \mathrm{L}$ of solution. Experimental design consisted in exposing larvae to six different concentrations of the main toxicant solution (four replicates) and to uncontaminated saltwater (control; six replicates). The multiwell plates were placed in the incubator for $24 \mathrm{~h}$ at $20^{\circ} \mathrm{C}$ and a $12 \mathrm{C} / 12 \mathrm{D}$ photoperiod. After the incubation was completed, the number of dead Artemia was counted and the percentage of mortality was calculated. The response parameter established for acute toxicity of light-stick content to larvae of Artemia was the lethal concentration for half of the tested organisms after $24 \mathrm{~h}$ of exposure $\left(24 \mathrm{~h}\right.$; $\left.\mathrm{LC}_{50}\right)$. This parameter was determined by the Trimmed Spearman-Karber method (Hamilton et al., 1977).

The second experiment evaluated the effect of light-stick content on cyst hatchability. It was similar to toxicity test with larvae, where one cyst was placed in each well. Test was performed with eight replicates for each of six exposure concentrations. After $48 \mathrm{~h}$ of incubation, the number of successfully hatched cyst (SHC) and non-successfully hatched cyst (NSHC) for each light-stick concentration was counted and the percentage of mortality was calculated. A SHC was defined as alive larvae after incubation. NSHC were separated in three groups: (1) non-hatched cyst, (2) partially hatched cyst, and (3) dead after hatched.

Data of SHC were expressed as mean \pm 1 S.E. $(\alpha=0.05)$. Significant differences between mean values of each light-stick concentration were assessed by one-way non-parametric analysis of variance (Kruskal-Wallis ANOVA).

\section{Results and discussion}

Estimated $24 \mathrm{~h}$; $\mathrm{LC}_{50}$ for nauplii exposed to light-stick content was $0.063\left(0.053-0.077 \mathrm{~mL} \mathrm{~L}^{-1}\right)$ (Fig. 1), while the LOEC (lowest observed effect concentration) was $0.04 \mathrm{~mL} \mathrm{~L}^{-1}$. Light-stick toxicity can be partially explained by evaluating the toxicity of its individual chemical compounds. Hydrogen peroxide $\left(\mathrm{H}_{2} \mathrm{O}_{2}\right)$, for example, is an important component of the light-stick solution (around 30\%), and it is known as a reactive oxygen species, ROS (Storey, 1996). While $\mathrm{H}_{2} \mathrm{O}_{2}$ per se is relatively harmless, Fenton's reactions can result in highly reactive ROS, such as hydroxyl radical and a hydroxyl anion, which are involved in numerous types of damage to cellular macromolecules (Storey, 1996). Several studies report the toxicity of $\mathrm{H}_{2} \mathrm{O}_{2}$ exposure to micro- or macro-organisms (Vallyathan, 1994; Barnes et al., 1996; Buyuksonmez et al., 1998; Gaikowski et al., 1999). However, the most comparable with the present investigation is a study with larvae of Artemia salina (Gavand et al., 2007). This species presented mortality of about $30 \%$ when exposed to $\mathrm{H}_{2} \mathrm{O}_{2}$ solution (100 ppm) for $20 \mathrm{~min}$, demonstrating the toxic capacity of this chemical to Artemia.

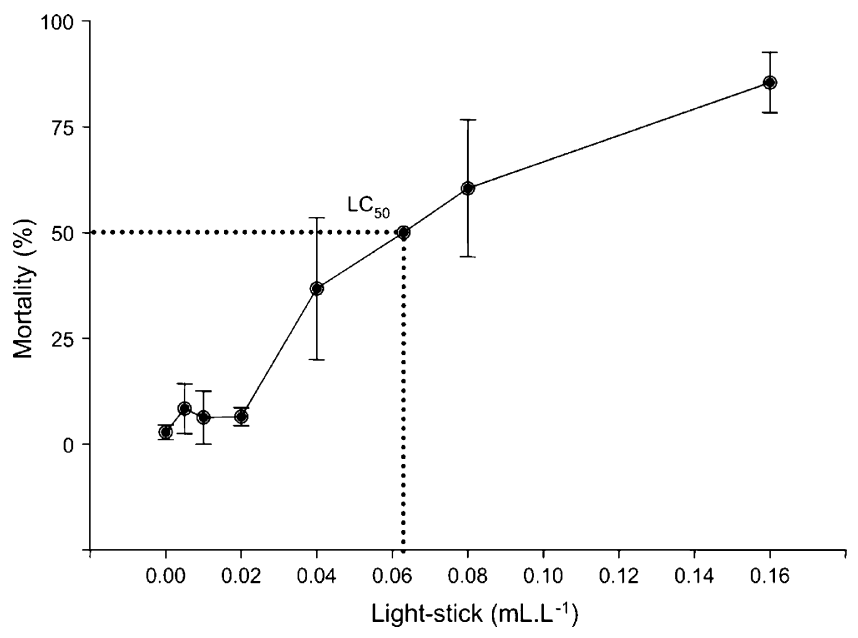

Fig. 1. Toxicity of light-stick content to Artemia sp.: \% of mortality in each tested concentration and calculated $24 \mathrm{~h} ; \mathrm{LC}_{50}$. Data are expressed as mean \pm S.E. $(n=6)$.

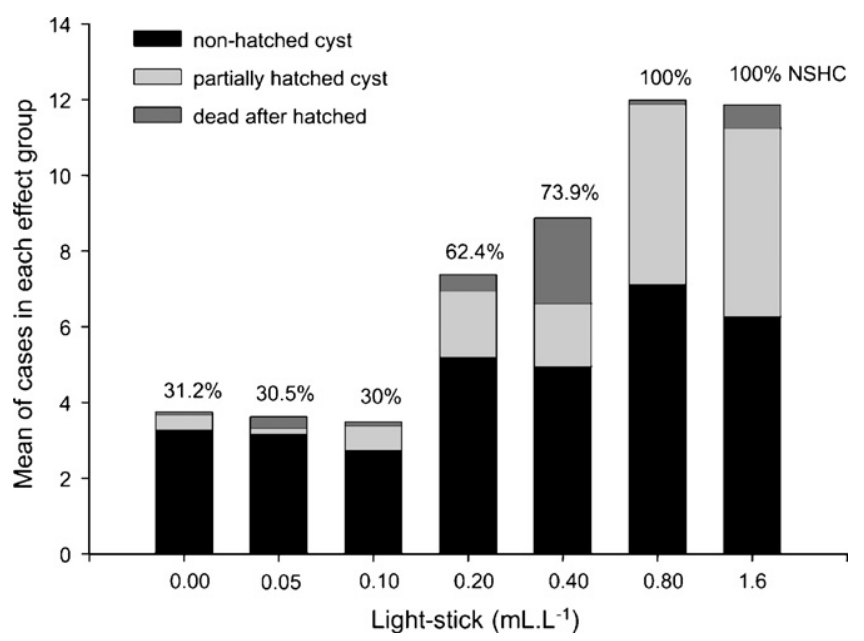

Fig. 2. Percentage of non-successfully hatched cyst (\% NSHC) and the specific effect (non-hatched cyst, partially hatched cyst and dead after hatched) in each tested concentration of light-stick content. Data are expressed as mean $(n=8)$.

Another potential responsible for light-stick toxicity is phthalate, the solvent present in the light-stick solution, since phthalate esters (dibutyl and dimethyl phthalate) were also shown to be toxic to cysts of $A$. salina (Sugawara, 1974).

The effect of light-stick content on cyst hatchability resulted in a LOEC of $0.2 \mathrm{mLL}^{-1}$ (Fig. 2). Regardless the robustness of cysts of Artemia, with a hard capsule covering a thick membrane, this capsule is likely to be susceptible either to oxidizing properties of $\mathrm{H}_{2} \mathrm{O}_{2}$ or to effects from phthalate ester exposure, or both.

The second solution in the light-stick tube is a mixture of oxalic acid bis ester, responsible by chemiluminescence and the orange dye solution. To date there is not any investigation about toxicity of both compounds.

In the present study, NSHC were separated in three groups: (1) non-hatched cyst, (2) partially hatched cyst, and (3) dead after hatched. The intention was to indicate the toxicant action of light-stick content on hatchability, which could result in a physical and/or chemical effect on the cyst. For example, a physical effect could be the adherence of light-stick solution onto the cyst surface, which could block hatching. A chemical effect would be observed whether the solution passes through the capsule and eventually killing the organism before hatching. Alternatively, a chemical action directly on the hatched organism is a possibility, in which it hatches but the organism dies due to exposure to the compounds.

Considering all tested concentrations, most of the effect of lightstick content solutions caused a non-hatched cyst effect followed by partially hatched cyst and dead after hatched (Fig. 2). It suggests a possible combination of physical and/or chemical effect on cyst surface, in which light-stick contents blocked a successfully hatch action. However, at the highest tested concentrations $(0.8$ and $1.6 \mathrm{mLL}^{-1}$ ) the toxicity to organisms was as important as to cysts, with enough chemical effect to kill the organisms during and after the hatching process.

In conclusion, the results of the present study indicate that light-stick content is toxic to Artemia sp. The effects were not only observed on the survival of nauplii, but also on the hatchability of cysts. Based on the findings of the present study and the complementary study of Ivar do Sul et al., 2007, it is suggested that light-stick content is potentially harmful to the marine environment. However, it must be taken in consideration that light-stick content is very unstable in environmental conditions and it is likely that none of these compounds might be present on their 
original form after some hours/days of exposure. Nevertheless, further studies regarding toxicity of light-stick (both new and used devices) to different organisms are needed, as well as chemical analyses of light-stick content to confirm its composition. Moreover, the toxicity of each compound of the light-stick should be evaluated for a better understanding of light-stick toxicity towards marine organisms, as well as the estimate lifetime of the light-stick before its content will impact receiving water.

\section{Conflict of interest}

None.

\section{Acknowledgements}

The authors thank to J.A. Ivar do Sul for providing the light-sticks and to B.A. Rodrigues, I.B. Giacomini, A.S. Filgueras, L.C. Portz, T. Tormena, M.H. Miranda and J.A. Ivar do Sul for help with experiments. G. Fillmann was sponsored by CNPQ (PQ 311459/2006-4) and P. Ihara by ANP (PRH 27).

\section{References}

Barnes, A.C., Horne, M.T., Ellis, A.E., 1996. Effects of iron and expression of superoxide dismutases by Aeromonas salmonicida and associated resistance to superoxide anion. FEMS Microbiol. Lett. 142, 19.

Bigelow, K., Musyl, M.K., Poisson, F., Kleiber, P., 2006. Pelagic longline gear depth and shoaling. Fish. Res. 77, 173.

Boggs, C.H., Ito, R.Y., 1993. Hawaii's pelagic fisheries. Mar. Fish. Rev. 55, 69.

Buyuksonmez, F., Hess, T.F., Crawford, R.L., Watts, R.J., 1998. Toxic effects of modified Fenton reactions on Xanthobacter flavus B71. Appl. Environ. Microbiol. 64, 3759.
Ermoshkin, A.A., Neckers, D.C., Federov, A.V., 2006. Photopolymerization without light. Polymerization of acrylates using oxalate esters and hydrogen peroxide. Macromolecules 39, 5669.

Gaikowski, M.P., Rach, J.J., Ramsay, R.T., 1999. Acute toxicity of hydrogen peroxide treatments to selected lifestages of cold-, cool-, and warmwater fish. Aquaculture $178,191$.

Gavand, M.R., McClintock, J.B., Amsler, C.D., Peters, R.W., Angus, R.A., 2007. Effects of sonication and advanced chemical oxidants on the unicellular green alga Dunaliella tertiolecta and cysts, larvae and adults of the brine shrimp Artemia salina: a prospective treatment to eradicate invasive organisms from ballast water. Mar. Pollut. Bull. 54, 1777.

Hamilton, M.A., Russo, R.C., Thurston, R.V., 1977. Trimmed Spearman-Karber: method for estimating median lethal concentration in toxicity bioassays. Environ. Technol. 11, 714

Hazin, H.G., Hazin, F.H.V., Travassos, P., Erzine, K., 2005. Effect of light-sticks and electralume attractors on surface-longline catches of swordfish (Xiphias gladius, Linnaeus, 1959) in the southwest equatorial Atlantic. Fish. Res. 72, 271.

Ivar do Sul, J.A., Rodrigues, O., Santos, I.R., Matthiensen, A., Fillmann, G., 2007. Skin irritation and histopathologic alterations in rats exposed to lightstick contents, UV radiation and seawater. In: Proceedings of the Fifth International Conference on Marine Pollution and Ecotoxicology, vol. 1, Hong Kong, p. 75.

Pedersen, A.D., Pommer, K., Hansen, P., Feilberg, A., Vagn, N., 2003. Survey of fluorescent substances in consumer products. Danish Technological Institute No. 40.

Santos, I.R., Friedrich, A.C., Ivar do Sul, J.A., in press. Marine debris contamination along undeveloped tropical beaches from northeast Brazil. Environ. Monit. Assess.

Storey, K.B., 1996. Oxidative stress: animal adaptations in nature. Braz. J. Med. Biol. Res. 29, 1715.

Sugawara, N., 1974. Toxic effect of a normal series of phthalate esters on the hatching of shrimp eggs. Toxicol. Appl. Pharmacol. 30, 87.

Vallyathan, V., 1994. Generation of oxygen radicals by minerals and its correlation to cytotoxicity. Oxygen radicals and lung injury. Environ. Health Perspect. 102, 111.

Wang, J.H., Boles, L.C., Higgins, B., Lohmann, K.J., 2007. Behavioural responses of sea turtles to lightsticks used in longline fisheries. Anim. Conserv. 10, 176

Witzell, W.N., 1999. Distribution and relative abundance of sea turtles caught incidentally by U.S. longline fleet in the western North Atlantic, 1992-1995. Fish. Bull. 97, 200. 